\title{
Development of Narrative Approach for Family Caregiver's QOL at Home Hospice and Contents of Narrative
}

\section{Michiyo Ando ${ }^{*}$, Hiroko Kukihara2 ${ }^{2}$ Mayumi Yamamoto ${ }^{3}$, Yasuyoshi Ninosaka ${ }^{4}$, Naoyuki Saito 5}

\author{
${ }^{1}$ Faculty of Nursing, St. Mary's College, Kurume, Japan \\ ${ }^{2}$ Faculty of Nursing, Fukuoka University, Fukuoka, Japan \\ ${ }^{3}$ School of Nursing at Fukuoka, International University of Health and Welfare, Fukuoka, Japan \\ ${ }^{4}$ Ninosaka Clinic, Fukuoka, Japan \\ ${ }^{5}$ Saito Clinic, Kurume, Japan \\ Email: ^andou@st-mary.ac.jp
}

How to cite this paper: Ando, M., Kukihara, H., Yamamoto, M., Ninosaka, Y., \& Saito, N. (2019). Development of Narrative Approach for Family Caregiver's QOL at Home Hospice and Contents of Narrative. Psychology, 10, 1407-1417.

https://doi.org/10.4236/psych.2019.1011092

Received: June 28, 2019

Accepted: August 12, 2019

Published: August 15, 2019

Copyright (c) 2019 by author(s) and Scientific Research Publishing Inc. This work is licensed under the Creative Commons Attribution International License (CC BY 4.0).

http://creativecommons.org/licenses/by/4.0/

\begin{abstract}
Goal: The aim of this study was the development of a narrative approach program for family caregivers at home hospice. We examined the effect on quality of life (QOL) and the factors of their narrative. Methods: Ten family caregivers who were taking care of a patient with a terminal illness at home at the time of the study participated voluntarily. They received two interviews in the narrative approach, in which they narrated about one hour per interview. They completed the questionnaires about quality of life (positive emotion in Caregiver Quality of life Index-Cancer: CQOLC), Life Satisfaction, and mental health (General Health Questionnaire: GHQ). Data was analyzed by quantitative and qualitative analysis. This study was approved by the Ethical Board at St. Mary's College. Results: The CQCLC score significantly increased $(p<$ 0.05 ) and the GHQ score decreased, though not to a significant extent. Life satisfaction didn't change because of ceiling effect. The categories about importance, changes after getting disease, hopes are selected. Conclusion: Narrative Approach may be useful to increase family caregiver's Quality of life (positive emotions), and have the possibility to reduce mental health problems. Selected categories suggested psychological process of caregivers, and that the narrative approach might promote the recognition of positive aspects or resilience. We propose a narrative approach program as a pilot study.
\end{abstract}

\section{Keywords}

Home Hospice, Narrative Approach, Caregiver, Quality of Life 


\section{Introduction}

Recently, the number of aging people is expected to increase in Japan and other countries. The location at the end of life is one of the most important things for many people. A previous study showed that about $70 \%$ people want to live and die in their home (Choi, Miyashita, Hirai, Sato, Morita, Tsuneto et al., 2010), however, only about $20 \%$ died in their home (Ministry of Health, Labor and Welfare, 2013). Similarly, in the United Kingdom, over 50\% of adults diagnosed with a terminal illness and the majority of people who have cancer, prefer to be cared for and to die in their own home according to Jack, Baldry, Groves, Whelan, Sephton, \& Gaunt (2013).

There are some literatures about family caregivers in home hospice. Family caregivers experience some difficulties. Ullrich, Ascherfeld, Marx, Bokemeyer, Bergelt, \& Oechsle (2017) showed that family caregivers of advanced cancer patients feel distress with sadness, sorrows and exhaustion, or anxiety and depression. Kozlov, Phongtankuel, Prigerson, Adelman, Shalvev, Czaja et al. (2019) indicated that family caregivers at home hospice had moderate-to severe anxiety or symptoms. Similarly Phongtankuel, Burchett, Shalev, Adelman, Prigerson, Czaja et al. (2019) expressed that family caregivers in home hospice experienced crisis like patient signs and symptoms, emotional distress, and caregiver burden. Thus we need some kind of intervention for family caregivers.

One of the interventions was the Narrative Approach. There is a narrative therapy by White \& Epson (1990) in which people create meaning from illness, suffering, and death through a narrative, by telling a story, (Stanley \& Hurst, 2011; Thomas, Reeve, Bingley, Brown, Payne, \& Lynch, 2009). Kleinman's work (1988) on illness narrative focused on the spoken words of patients. ${ }^{10}$ It may be basic of narrative approach. We sometimes confront traumatic life events, such as being diagnosed with a chronic or terminal illness. These kinds of events are strongly effective on our self-identity and are needed to change our life. A social psychologist Elliot Mishler (Mishler, 1999) says that identity development is an interpersonal process involving the telling and retelling of stories about the self to others. In his theory, narrative has potential to change self-identity to adapt traumatic events. In clinical situation, Noble \& Jones (2005) showed the benefit of narrative therapy such that narrative therapeutic approaches allow the patients and the family to tell their stories and find meaning in them to allow a state of acceptance and comfort. The narrative approach may be useful for family caregivers' psychological health. This approach was effective on depression or wellbeing of advanced cancer patients (Lloyd-Williams, Shiels, Ellis, Abba, Gaynor, Wilson et al., 2017; Wise, Marchand, Roberts, \& Chih, 2018), however, there were few studies about family caregivers. Thus, a narrative approach program was created for the present study which examined psychological aspects of quality of life, life satisfaction, mental health, and contents of narratives.

\section{Methods}

Participants: We attempted to recruit 12 family caregivers, two declined to par- 
ticipate, and ten participated. The patients were receiving treatment from three kinds of clinics in Japan (Table 1). The patients whose family caregivers took care of them had low physical power, like Performance Status (PS) (Oken, Creech, Tormey, Horton, Davis, McFadd et al., 1982) from 2 to 4 . The stage of a patient's cancer was " 4 " or was a recurrence. The inclusion criteria were a family member who was currently taking care of the patient via home hospice, was aged $\geq 20$ years old, and could discuss their situation for 60 minutes. The exclusion criteria were patients with cognitive impairment or serious mental illness.

Questionnaires: We used the Japanese version CQOLC (Ando, Harata, Weitzner, Kuji, Shimizu, Sato et al., 2013) which is based on the original version Weitzner, Jacobsen, Wagner, Friedland, \& Cox (1999) to examined quality of life. In this scale, we used positive emotion ( 5 items). To test life satisfaction, we used the Satisfaction with Life Scales Japanese version Kadono (1994) based on the original version (Diener, Emmons, Larsen, \& Griffin, 1985). To test mental health, we used the General Health Questionnaire Japanese version (Nakagawa \& Daibo, 1985), based on the original (Goldberg, 1978).

Procedure: The primary physician introduced the study to a family caregiver who met the inclusion criteria. Family caregivers who showed interest were registered and the researchers sent a letter about the research. After sending the letter, the researcher explained the details of the study to the candidate via telephone. If he or she agreed to participate, they decided the place and time for an interview. The interviewer visited a family caregiver's home or a clinic, explained about the research again, and received informed consent after agreement for participation.

In the Narrative approach, there were two sessions. We prepared some questions referring to previous studies to promote the family caregiver's narratives (Lloyd-Williams et al., 2017; Wise et al., 2018).

Table 1. Background of family caregivers.

\begin{tabular}{|c|c|c|c|c|c|c|c|c|c|}
\hline ID & Age & Gender & $\begin{array}{l}\text { Relationships } \\
\text { for a patient }\end{array}$ & Patients' disease & Disease stage & $\begin{array}{l}\text { PS of a } \\
\text { patient }\end{array}$ & $\begin{array}{l}\text { Duration of } \\
\text { care }\end{array}$ & Substitute & Burden (1 - 5) \\
\hline ID 1 & 60 & $\mathrm{~F}$ & Wife & Lung & 4 & 4 & 2 years & $\mathrm{N}$ & 2 \\
\hline ID 2 & 70 & $\mathrm{~F}$ & Child & Colon & 4 & 4 & 1 year & $\mathrm{N}$ & 2 \\
\hline ID 3 & 50 & $\mathrm{~F}$ & Wife & ATL & 4 & 4 & 2.5 years & $\mathrm{N}$ & 2 \\
\hline ID 4 & 50 & $\mathrm{~F}$ & Wife & Lung & 4 & 2 & 4 month & $\mathrm{N}$ & 2 \\
\hline ID 5 & 60 & $\mathrm{~F}$ & Child & Hurtfailure & terminal & 2 & 6 years & $\mathrm{N}$ & 1 \\
\hline ID 6 & 80 & $\mathrm{~F}$ & Wife & Stomach & 4 & 3 & 2 years & $\mathrm{Y}$ & 1 \\
\hline ID 7 & 30 & $\mathrm{~F}$ & Child & Stomach & 4 & 2 & 2 years & $\mathrm{N}$ & 2 \\
\hline ID 8 & 60 & $\mathrm{~F}$ & Wife & Prostate cancer & Recuurence & 3 & 1 years & $\mathrm{N}$ & 3 \\
\hline ID 9 & 70 & $\mathrm{~F}$ & Wife & Labor & Recuurence & 3 & 2.5 years & $\mathrm{N}$ & 3 \\
\hline ID 10 & 30 & $\mathrm{~F}$ & Child & Lung & 4 & 4 & 4 month & $\mathrm{Y}$ & 4 \\
\hline
\end{tabular}


In the first session, there were some questions about reasons for the decision to take care of a loved one (patient) at home hospice, beneficial points and difficulties of home hospice. In the second session, there were some questions about "Important things for family caregivers," "Changes (growth) for family caregivers," and "Hopes of family caregivers." With participants' permission, their narratives were recorded on IC recorders. Before the first session and after the second session, the participants completed questionnaires. Each session lasted about 60 minutes. They completed some psychological questionnaires; these quantitative results are reported on another occasion. This study was approved by the ethical boards of St. Mary's College.

Analysis: For the scores of questionnaires, we used Wilcoxon-test statistically. For the narrative data, we employed "qualitative analysis" by Funashim (2001) based on the work of Berelson (1952) which involves creating codes, subcategories and categories. Though we asked beneficial points and difficult points in the first session, we will report in other occasion. We analyzed the narrative in the second session about importance, changes, and hopes, because these narrative seemed to be related to psychological process of caregivers. These narratives were edited into a shortest statement without losing meanings and coded into one subcategory along with similar statements. Similar subcategories were then integrated into one category. To maintain reliability, categorization and coding were validated independently by researchers. Inconsistencies were discussed and negotiated until agreement was reached.

\section{Results}

The factor of positive emotion in the CQOLC score significantly increased from 23 to 24.8 statistically $(p<0.05)$. The Life satisfaction score remained almost the same, changing from 21.0 to 21.5 . Though the GHQ score decreased from 13.0 to 11.3 , there was no significant difference.

We selected categories from narratives about importance, changes, and hopes. We indicate the subcategory with $<>$ and category with " ".

Regarding importance, we chose four categories (Table 2). Category “1) Family relationships" included subcategories like $<$ My children's happiness $><M y$ family and brother have good relationship $>$. "2) Relationships with people" included subcategories like <Relationships with people $><$ Feeling thankful for others $>$. The category “3) Spending every day" included sub-categories like $<$ Fulfilling patients' hopes $>$ or $<$ Spending every day calmly $>$. The category "4) My thinking and rearrangement of my life" included sub-categories like $<$ My thinking or idea $>$ or $<$ My rearrangement $>$.

About change (growth) points with home hospice, there are seven categories (Table 3). The category “5) Limited my life by caregiving” included subcategories like $<$ My relationships are limited $>$ or $<$ I always think of a loved one $>$. The category “6) Understanding requirements from others' help" included subcategories like $<$ There is no emotional outlet $>$ or $<$ The visiting physicians 
and nurse helped us>. The category "7) Thinking of feelings between those who receive care and caregiver" included subcategories like <There is difference in opinion between a patient and a caregiver $>$ or $<\mathrm{I}$ had no understanding of the feelings of caregivers $>$. The Category " 8 ) Becoming tender after being used to care" included subcategories like $<$ I was not kind when I was not used to care $>$ or $<$ I became tender $>$. The category "9) Waiting for a loved one" included subcategories like $<$ A loved one moves slowly $>$ or $<$ I could wait for his slow movement $>$. The category "10) Having the intention to continue caregiving" included subcategories like $<$ A loved one became well and I enjoyed free time $>$. The category “11) Thinking of caregiver's end of life" included subcategory like $<$ I think about things after a loved one's death $>$.

About hopes for the future, there are four categories (Table 4). The category “12) Hope to go out together" included subcategories like $<$ We used to go out together $>$ or $<$ I hope to go on a family trip $>$. The category "13) Enrichment of left time" included subcategories like $<$ We live remaining time richly $>$ or $<\mathrm{I}$ don't worry too much $>$. The category "14) Helping a loved one's hope come true" included subcategories $<$ Home hospice is a loved one's hope $>$ or $<$ A loved one hopes for a natural death>. The Category "15) Thinking of family caregiver's own end of life" included $<$ A family caregiver thinks of their end of life $>$ or $<$ A family caregiver thinks after a loved one's death $>$.

Table 2. Important things for family caregiver.

\begin{tabular}{|c|c|c|}
\hline Code & subcategory & category \\
\hline $\begin{array}{l}\text { - I hope that my children will be happy. } \\
\text { - Happiness of my children is my happiness. }\end{array}$ & - My child's happiness & 1) Family relationship \\
\hline $\begin{array}{l}\text { - Martial relationships is important. } \\
\text { - My husband is important. }\end{array}$ & - Marital relationship & \\
\hline $\begin{array}{l}\text { - My family and friends are important. } \\
\text { - My family and brothers have good relationships. }\end{array}$ & - My family and brother have good relationship & \\
\hline $\begin{array}{l}\text { - Relationships with others is important. } \\
\text { - Daily relationships with people is important. }\end{array}$ & - Relationships with people & 2) Relationships with people \\
\hline $\begin{array}{l}\text { - My mother says that thanks is important. } \\
\text { - I keep in mind to say thanks. }\end{array}$ & - Feeling thankful for others & \\
\hline - I try to fulfill my husband's hope. & - Full filing patient' hope & 3) Spending every day \\
\hline $\begin{array}{l}\text { - I tried to spend every day calmly. } \\
\text { - I hope that this condition will continue. }\end{array}$ & - Spending every day calmly & \\
\hline $\begin{array}{l}\text { My thinking (idea) is important. } \\
\text { - I get needed information. }\end{array}$ & - My thinking or idea & $\begin{array}{l}\text { 4) My thinking and } \\
\text { rearrangement of my life }\end{array}$ \\
\hline $\begin{array}{l}\text { - I will rearrange my life. } \\
\text { - I prepare no matter what happened. }\end{array}$ & - My rearrangement & \\
\hline
\end{tabular}


Table 3. Family Caregiver's changes through care.

\begin{tabular}{|c|c|c|}
\hline Code & Subcategory & Category \\
\hline $\begin{array}{l}\text { - I couldn't use my time freely. } \\
\text { - I can't go to lunch due to taking care of a loved one. }\end{array}$ & - My relationships are limited. & 5) Limited my life by caregiving \\
\hline $\begin{array}{l}\text { - I always think of a loved one. } \\
\text { - I tried to hurry to do everything. }\end{array}$ & - I always think of a loved one. & \\
\hline $\begin{array}{l}\text { - I'm sometimes irritated because of different opinions. } \\
\text { - My emotion sometimes explodes. }\end{array}$ & - There is no emotional outlet. & $\begin{array}{l}\text { 6) Understanding requirements } \\
\text { from others' help }\end{array}$ \\
\hline $\begin{array}{l}\text { - A loved one and a physician made good relationships. } \\
\text { - A visiting nurse answered my questions and unease. } \\
\text { - Understanding difficulty of caretaking, I know others' } \\
\text { help is required. }\end{array}$ & - The visiting physician and nurse helped us. & \\
\hline $\begin{array}{l}\text { - I tried to go out when a loved one was not well. } \\
\text { - A loved one mentioned his dissatisfaction to me. } \\
\text { - I decrease my frequency of going out. }\end{array}$ & $\begin{array}{l}\text { - There is difference } \\
\text { in opinion between } \\
\text { a patient and a caregiver. }\end{array}$ & $\begin{array}{l}\text { 7) Thinking of feelings between } \\
\text { those who receive care and } \\
\text { caregiver }\end{array}$ \\
\hline $\begin{array}{l}\text { - I had no understanding of the feelings of caregivers. } \\
\text { - I will not give the burden of care to my family. }\end{array}$ & - I had no understand of feeling of caregiver. & \\
\hline
\end{tabular}

- I was not kind when I was not used to care.

- Daughters considered my care.

- I became tender after being used to care.

- A loved one sometimes lost his way.

- I worried about his safety when a loved one went out.

- A loved one can't move

- I made a loved one hurry up before.

- A loved one moves slowly.

- I accepted his slowness.

- I could wait for his slowness without irritation.

- I ate too much for continued caregiving.

- Eating is my best pleasure.

- I try to maintain my physical strength.

\section{8) Becoming tender after being} used to care.

- I became tender.

- I worried about a loved one's behavior.

- I could wait for his slow movement.

- A loved one was settled down by medication.

- I went to the gym.

- A loved one became well and a caregiver enjoyed free time.

- Communication was promoted.

- A loved one had chance to talk with me about gym.

- I am relaxed.

10) Having the intention to continue caregiving

9) Waiting for a loved one
- I began to think of the future.

- I considered my sister in law. fe 
Table 4. Hope for the future.

\begin{tabular}{|c|c|c|}
\hline Code & subcategory & category \\
\hline $\begin{array}{l}\text { - A loved one worries and has stopped to go out. } \\
\text { - A family caregiver want to go out together. }\end{array}$ & - We used to go out together. & $\begin{array}{l}\text { 12) Hope to go out } \\
\text { together }\end{array}$ \\
\hline $\begin{array}{l}\text { - My family used to go on trips. } \\
\text { - I hope to go to hot springs. }\end{array}$ & - I hope to go on a family trip. & \\
\hline $\begin{array}{l}\text { - My husband and I will live remaining time richly. } \\
\text { - Doing what a loved one wants is the best. }\end{array}$ & - We live remaining time richly. & $\begin{array}{l}\text { 13) Enrichment of } \\
\text { left time }\end{array}$ \\
\hline $\begin{array}{l}\text { - I do not worry too much. } \\
\text { - Almost troubles is solved when I consult a physician. }\end{array}$ & - I don't worry too much. & \\
\hline $\begin{array}{l}\text { - I want my father's hope to come true. } \\
\text { - Home hospice is his hope and we are relaxed. } \\
\text { - Father hoped for a natural death. } \\
\text { - It is good that a loved one does not suffer. }\end{array}$ & - A love one hopes for natural death & $\begin{array}{l}\text { 14) Helping a loved one's } \\
\text { hope come true }\end{array}$ \\
\hline $\begin{array}{l}\text { - I think about my end of life. } \\
\text { - I wrote a "A Will" note. }\end{array}$ & - A family caregiver thinks about their end of life. & $\begin{array}{l}\text { 15) Thinking of family } \\
\text { caregivers' own end of life }\end{array}$ \\
\hline $\begin{array}{l}\text { - I will make many friends and interact with others } \\
\text { smoothly. }\end{array}$ & - A family caregiver thinks about after a loved one's death. & \\
\hline
\end{tabular}

These categories are summed up in psychological process of family caregivers (Figure 1). Family caregivers recognized family relationships or spending everyday carefully as important. They were not used to care of a loved one, confront differences of feeling between a loved one and themselves and reflected them, and understood a loved ones feeling and accepted care. Then they hoped to enrich left time. Through these experiences, family caregiver gain a family resilience and positive emotion might increase.

\section{Discussion}

The positive emotion score in the CQOLC of family caregivers significantly increased, which shows that the Narrative Approach may improve their quality of life. In the Narrative Approach, they could tell their stories with a loved one and reconstruct their lives within the illness or caregiving and found meaning in their life. Narratives have the potential to reconstruct a human story (Stanley \& Hurst, 2011). Thus their QOL may increase.

About the Life Satisfaction scale, 21 points is the same as the standard score of healthy persons (Kadono, 1994). Even though family caregiver in the present study took care of a loved one and have some burden, their life satisfaction score was the same level as ordinary people. This may mean that they are satisfied with their lives with care. In the narrative categories, they found importance such as relationships with families and recognized them. This recognition may relate to their life satisfaction. About their mental health, a decrease of the GHQ score may have the potential to decrease family caregivers' stress or burdens. We need to examine and confirm the results again. 
[ Recognize importance]

- Caregivers recognized relationships as importance.

- They wanted to spend every day carefully.

[Feeling changes]

1. Family care givers felt restricted time and not used to care.

2. They reflected their care and relationships.

3. They became understand a loved one and accepted.

\section{[Finding hope ]}

- Family caregivers hoped to enrich left time

- They hope to come true of a loved ones' hope

\section{Family Resilience}

Figure 1. Psychological process of family caregivers.

About the categories for the important things, family caregivers recognized the importance of family relationships or relationships with people. Bereaved family members who took care of a loved one also perceived that "family" was important (Ando, Morita, Miyashita, Sanjyo, Kira, \& Shima, 2011). In usual busy life, we forget importance, we may rethink what is important when people confront traumatic problems.

About changes through caring at home hospice, family caregivers felt restrictions of their daily life or the difficulty of caring only by themselves, or felt differences of opinions between a loved one and a family caregiver. They became tender to a loved one or were able to wait for his or her slowness. It is the process for a family to recover from crisis and return to daily life, and we can also say it is resilience. Resilience is the power of recovery to the state before difficult work. McDonald, Swami, Pope, Hales, Nissim, Rodin et al. (2018) investigated the quality of life of caregivers and showed "maintaining resilience." Moreover, Li, Qiao, Luan, Li, \& Wang, (2019) showed that resilience of caregivers of cancer patients contributed to QOL of caregiver burden. These previous studies show that resilience may be related to QOL. In the present study, the Narrative Approach promotes the recognition of their changes or growth and increases resilience and QOL.

As for categories about "Hopes," family caregivers mainly hoped to live remaining time richly with a loved one and to care for them until the last moment. Toward the last stage, a family caregiver may experience crisis. In that case, physical, psychological, and spiritual support for them will be needed.

Lastly, we demonstrate our Narrative Approach program (Table 5) which we used in this study. In future we will need to confirm the utility of the program much more. 
Table 5. A Narrative Approach program for family caregiver in home hospice.

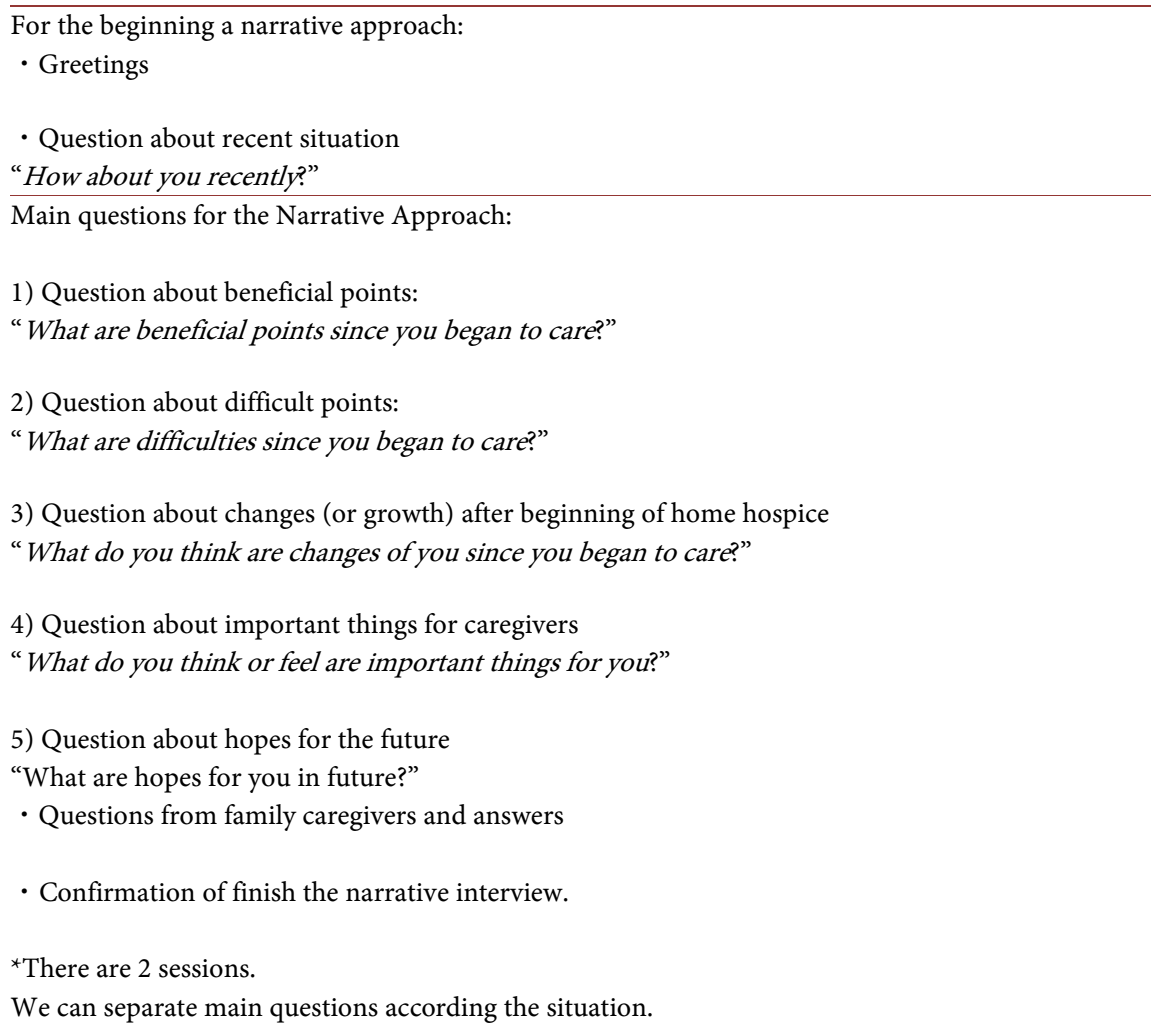

\section{Conclusion}

The Narrative Approach program may be useful to increase positive emotion in quality of life and has possibility to decrease mental health problems. Though family caregivers were not used to care of a loved one, they gain resilience and have intention to continue care in home hospice.

\section{Fund}

This study is supported by JSPS KAKENHI (17K12559).

\section{Conflicts of Interest}

The authors declare no conflicts of interest regarding the publication of this paper.

\section{References}

Ando, M., Morita, T., Miyashita, M., Sanjyo, M., Kira, H., \& Shima, Y. (2011). Factors That Influence the Efficacy of Bereavement Life Review Therapy for Spiritual WellBeing: A Qualitative Analysis. Supportive Care in Cancer, 19, 30-314. https://doi.org/10.1007/s00520-010-1006-7

Ando, S., Harata, M., Weitzner, M. A., Kuji, M., Shimizu, M., Sato, K., \& Miyashita, M. (2013). Reliability and Validity of Japanese Version Caregiver Quality of Life Index-Cancer (CQOLC). Palliative Care Research, 8, 286-292. “

Berelson, B. (1952). Content Analysis. New York, Free Press. 
Choi, J., Miyahita, M., Hirai, K., Sato, K., Morita, T., Tsuneto, S., \& Shima, Y. (2010). Preference of Place for End-of-Life Cancer Care and Death among Bereaved Japanese Families Who Experience Home Hospice Care and Death of Loved One. Supportive Care in Cancer, 18, 1445-1453. https://doi.org/10.1007/s00520-009-0767-3

Diener, E., Emmons, R. A., Larsen, R. J., \& Griffin, S. (1985). The Satisfaction with Life Scale. Journal of Personal Assessment, 49, 71-75. https://doi.org/10.1207/s15327752jpa4901_13

Funashim, N. (2001). Challenges in Qualitative Analysis (In Japanese). Tokyo: Igakusyoin.

Goldberg, D. (1978). Manual of the General Health Questionnaire. Windsor: Nfer-Nelson.

Jack, B. A., Baldry, C. R., Groves, K. E., Whelan, A., Sephton, J., \& Gaunt, K. (2013). Supporting Home Care for the Dying :An Evaluation of Healthcare Professionals' Perspectives of an Individually Tailored Hospice at Home Service. Journal of Clinical Nursing, 22, 2278-2286. https://doi.org/10.1111/j.1365-2702.2012.04301.x

Kadono, Z. (1994). A Pilot Study of Making a Japanese Version Satisfaction with Life Scale (SWLS). Proceeding of Annual Japanese Association Educational Psychology, 36, 192.

Kleinman, A. (1988). The Illness Narratives: Suffering, Healing and the Human Condition. New York: Basic Books.

Kozlov, E., Phongtankuel, V., Prigerson, H., Adelman, R., Shalev, A., Czaja, S. et al. (2019). Prevalence, Severity, and Correlates of Symptoms of Anxiety and Depression at the very End of Life. Journal of Pain Symtom Management, 58, 80-85. https://doi.org/10.1016/j.jpainsymman.2019.04.012

Li, Y. L., Qiao, Y. J., Luan, X. R., Li, S. J., \& Wang, K. F. (2019). Family Resilience and Psychological Well-Being among Chinese Breast Cancer Survivors and Their Caregivers. European Journal of Cancer Care, 28, e12984. https://doi.org/10.1111/ecc.12984

Lloyd-Williams, M., Shiels, C., Ellis, J., Abba, K., Gaynor, E., Wilson, K. et al. (2017). Pilot Randomized Controlled Trial or Focused Narrative Intervention for Moderate to Severe Depression in Palliative Care Patients: DISCERN Trial. Palliative Medicine, 32, 206-215. https://doi.org/10.1177/0269216317711322

McDonald, J., Swami, N., Pope, A., Hales, S., Nissim, R., Rodin, G. et al. (2018). Caregiver Quality of Life in Advanced Cancer: Qualitative Results from a Trial of Early Palliative Care. Palliative Medicine, 32, 69-78. https://doi.org/10.1177/0269216317739806

Ministry of Health, Labor and Welfare (2013). http://www.mhlw.go.jp/stf/shingi/

Mishler, E. G. (1999). Storylines. Craft Artists' Narratives of Identity. Cambridge, MA: Harvard University Press.

Nakagawa, T., \& Daibo, I. (1985). The General Health Questionnaire-Japanese Version. Tokyo: Nihonbunkagakusya.

Noble, A., \& Jones, C. (2005). Benefits of Narrative Therapy Holistic Interventions at the End of Life. British Journal of Nursing, 14, 330-333. https://doi.org/10.12968/bjon.2005.14.6.17802

Oken, M. M., Creech, R. H., Tormey, D. C., Horton, J., Davis, E. E., McFadd, E. T. et al. (1982). Toxicity and Response Criteria of the Eastern Cooperative Oncology Group. American Journal of Clinical Oncology, 5, 649-656. https://doi.org/10.1097/00000421-198212000-00014

Phongtankuel, V., Burchett, C. O., Shalev, A., Adelman, R. D., Prigerson, H. G., Czaja, S. J. et al. (2019). Perception of a Home Hospice Crisis: An Exploratory Study of Family Caregivers. Journal of Palliative Medicine. https://doi.org/10.1089/jpm.2018.0511 
Stanley, P., \& Hurst, M. (2011). Narrative Palliative Care: A Method for Building Empathy. Journal of Social Work in End of Life \& Palliative Care, 7, 39-50. https://doi.org/10.1080/15524256.2011.548046

Thomas, C., Reeve, J., Bingley, A., Brown, J., Payne, S., \& Lynch, T. (2009). Narrative Research Methods in Palliative Care Context: Two Case Studies. Journal of Pain and Symptom Management, 37, 788-796.

https://doi.org/10.1016/j.jpainsymman.2008.05.006

Ullrich, A., Ascherfeld, L., Marx, G., Bokemeyer, C., Bergelt, C., \& Oechsle, K. (2017). Quality of Life, Psychological Burden, Needs, and Satifaction during Specialized in Patien Palliative Care in Family Caregivers of Advanced Cancer Patients. BMC Palliative Care, 10, Article No. 31. https://doi.org/10.1186/s12904-017-0206-Z

Weitzner, M. A., Jacobsen, P. B., Wagner, H., Friedland, J., \& Cox, C. (1999). The Caregiver Quality of Life Index-Cancer (CQOLC) Scale: Development and Validation of an Instrument to Measure Quality of Life of the Family Caregiver of Patients with Cancer. Quality of Life Research, 8, 55-63. https://doi.org/10.1023/A:1026407010614

White, M., \& Epson, D. (1990). Narrative Means to Therapeutic Ends. New York: Norton.

Wise, M., Marchand, L. R., Roberts, L. J., \& Chih, M. Y. (2018). Suffering in Advanced Cancer: A Randomized Control Trial of a Narrative Intervention. Journal of Palliative Medicine, 21, 200-207. https://doi.org/10.1089/jpm.2017.0007 